\title{
REVIEW ETNOAGRONOMI PERLADANGAN PANGAN DI INDONESIA
}

\author{
Review: Etno-agronomy of Upland Food Crop Systems in Indonesia \\ Rusdi Evizal ${ }^{1) *}$ \\ 1) Jurusan Agronomi dan Hortikultura, Fakultas Pertanian, Universitas Lampung \\ Jln. Sumantri Brojonegoro No. 1 Gedung Meneng, Bandar Lampung 35145 \\ *E-mail: rusdi.evizal@fp.unila.ac.id
}

\begin{abstract}
ABSTRAK
Sistem perladangan diterapkan pada sistem ladangan berpindah maupun perladangan menetap di lahan kering maupun lahan sawah tadah hujan di musim kemarau. Sistem perladangan berperan penting dalam produksi dan ketahanan pangan petani. Transformasi dari sistem pengumpulan hasil hutan menjadi sistem perladangan menetap dan perkebunan dibahas dalam review ini. Selain itu didiskusikan etnoagronomi beberapa tanaman pangan penting dan potensial seperti sagu, ubi jalar, uwi, talas, jewawut, dan hanjeli.
\end{abstract}

Kata kunci: pangan, perladangan, sagu, ubi jalar, uwi, talas, jewawut, hanjeli

\section{ABSTRACT}

Traditional field crop systems are practiced in both shifting cultivation systems and settled cultivation system. Traditional upland cropping systems play an important role in the production and food security of farmers. Transformation of the settled cultivation systems and plantations from the system of collecting forest products and shifting cultivation in Indonesia is discussed in this review. Futhermore we discuss ethno-agronomy of several traditional staple crop including sago, sweet potato, yam, taro, foxtail millet, and Coix lacryma-jobi

Keywords: Coix lacryma-jobi, foxtail millet, sago, sweet potato, yam, taro, shifting cultivation

\section{PERLADANGAN PANGAN}

Perladangan adalah sistem pertanian tradisional Indonesia yang masih dipraktekkan terutama oleh masyarakat tradisional, masyarakat adat, suku-suku pedalaman, masyarakat di wilayah terpencil, pegunungan dan perbatasan hutan yang disebut endogenous people. Peladang dari masyarakat terpencil umumnya perupakan petani subsisten dengan penghidupan yang sederhana yang sering dikategorikan sebagai petani miskin. Jumlahnya tidak diketahui pasti namun diperkirakan merupakan sepertiga dari masyarakat termiskin di pedesaan (Erni, 2015). Bagi masyarakat adat yang sangat tradisional seperti suku-suku
Dayak di Kalimantan dan Suku Baduy di Banten maka berladang (berhuma, berhuma, beume) merupakan budidaya padi dan tanaman lainnya untuk memenuhi kebutuhan hidup terutama beras, sayur, dan bumbu sedangkan berkebun (lada, kelapa, pisang) sebagian untuk dijual atau ditukar dengan keperluan hidup seperti garam, gula, dan tembakau (Lahajir, 2001; Dove, 1988). Berladang berpindah mencakup budidaya tanaman pangan di lahan darat dan dataran tinggi, lahan rawa, dan pasang surut sesuai kearifan lokal yang masyarakat miliki dalam mengusahakan lahan dan mengembangkan sumberdaya genetik lokal (Raharjo et al., 2015). 
Praktek sistem pertanian ini bervariasi dan mengalami trasnformasi yang dimulai dari sistem ladang berpindah menuju sistem pertanian menetap yang disebut pertanian pangan (ladang, atau, tegal, atau kebun singkong, jagung, ubi rambat), hortikultura (ladang atau kebun sayur dan buah) dan perkebunan rakyat (kebun karet, kopi, lada, cengkeh, kayu manis, kelapa, durian, rambutan, manggis, duku, salak). Banyak istilah untuk menamai sistem perladangan bepindah antara lain disebut shifting cultivation yang bermakna pertanian berpindah, merupakan istilah yang paling banyak diigunakan (Iskandar, 1992) dan laporan FAO juga menggunakan istilah ini. Sistem perladangan berpindah sering disebut swidden agriculture yang dalam Bahasa Inggris kuno bermakna membuka lahan dengan cara membakar (burnt clearing) yang berkonotasi negatif (Erni, 2015) antara lain dengan pembakaran akan menumbuhkan padang alang-alang sebagai bagian dari suksesi menjadi hutan (Dove, 1983).

Selain itu sistem perladangan disebut juga sistem slash-and-burn yang artinya sistem tebas dan bakar yang lebih menonjolkan sikap menyalahkan (prejudicial) sebagai sistem merusak hutan dengan cara menebang dan membakar sehingga muncul istilah rotational farming yang bermakna pertanian secara rotasi. Pemahaman ini menekankan sebagai sistem yang merotasikan penggunaan lahan (land use cycling) umumnya dengan pemberoan (fallowing) sehingga vegetasi secara alami menutupi lahan dan bersuksesi alami dari semak menjadi hutan sekunder dan siap dibuka kembali atau setengah pemberoan (semi-fallowing) dengan menanami tanaman keras perkebunan seperti karet di Jambi tanpa perawatan intensif menjadi hutan karet (Evizal, 2008) sebagai suksesi yang dibantu manusia atau menjadi hutan damar Mata Kucing di Lampung Barat (Foresta et al., 2000) dan kopi di Sumatera Selatan dan Lampung sampai saatnya kembali dibuka sebagai ladang (Evizal, 2013).
Sebagai bagian dari sistem rotational farming yang dinamis atau sistem pertanian menetap, baik ladang, tegal atau kebun maka sistem perladang merupakan awal dari sistem pertanian menetap atau merupakan sistem perladangan pionir. Penggolongan ini berbeda dengan yang dimaksud oleh Conklin (1957) dalam Cramb (2009) yang menyebut sistem perladangan pionir (pioneer shifting cultivation) adalah sistem perladangan yang membuka hutan primer, sedangkan sistem perladangan berpindah (established shifting cultivation) membuka ladang dari hutan sekunder karena rotasi penggunaan lahan melibatkan dan bersiklus pada hutan sekunder. Sedangkan yang saya maksudkan dengan sistem perladangan pionir adalah sistem yang membuka hutan primer atau sekunder untuk berladang dan selanjutnya berkembang menjadi penggunaan lahan yang mantap. Apabila lahan kembali beregenerasi menjadi hutan sekunder dan diladangi kembali maka sistem tersebut merupakan sistem ladang berpindah yang sesungguhnya yaitu established shifting cultivation.

Berikut ini akan dibahas sistem perladangan dari dua pemahaman tersebut yaitu (1) sistem perladangan berpindah dan (2) sistem perladangan pionir yang keduanya merupakan sistem produksi pangan terutama beras untuk keperluan kebutuhan penghidupan subsisten. Dalam perspektif historis dan georafis Cramb (2009) membagi sistem pertanian di Serawak dalam 3 tahap transisi yaitu (1) transisi dari pengumpulan hasil hutan ke sistem perladangan berpindah, (2) transisi perladangan berpindah ke perkebunan rakyat, (3) transisi perladangan berpindah dan perkebunan rakyat ke perkebunan besar. Dalam perspektif ini, sistem perkebunan berkembang ke arah produki pangan (non beras) dan bahan baku industri yang berlangsung ekspansif dan intensif dalam pengelolaan sumberdaya alam. Menurut Barlow and Jayasuriya (1986) dalam Cramb (2009) perkembangan sistem perkebunan rakyat melalui 3 fase yaitu: (1) Mengentas dari subsistensi, ketika 
produksi subsisten ditambahi (suplemen) oleh tanaman perkebunan, penggunaan tenaga kerja yang intensif, dan adopsi agroteknologi tanaman (2) transformasi pertanian (agriculture transformation) ketika perkebunan rakyat menjadi lebih besar dan komersial, adopsi agroteknologi yang lebih produktif, (3) perubahan structural lanjutan (extended structural exchange), ditandai peningkatan yang signifikan sektor industri dan jasa serta sektor pertanian tidak lagi domiman mengakibatkan perkebunan rakyat menjadi kurang menguntungkan karena peningkatan biaya lahan dan tenaga kerja.

\section{PENGUMPULAN HASIL HUTAN KE PERLADANGAN}

Fase-fase perkembangan sistem pertanian primitif menjadi pertanian modern sering dilaporkan pada hasil studi etnobotani di Borneo yang memiliki potensi hutan yang luas dan suku Serawak dan Dayak dan di Papua dengan banyak suku Papua sebagai endogenous people (lihat Dove, 1988; Lahajir, 2001; Cramb, 2009; Hujairin et al., 2017; Michael, 2020). Pada mulanya masyarakat memperoleh pangan dengan mencari di hutan berupa sagu, aren, ubi jalar, talas, singkong, sayur dan buah. Selain itu mereka berburu dan mencari ikan. Pada beberapa wilayah adat yang kuat dapat ditemukan sistem ladang berpindah, sistem ladang menetap, kebun, dan hutan. Misalnya Hujairin et al. (2017) melaporkan bahwa masyarakat Suku Arfak, Papua, membagi 4 wilayah atau jenis lahan yaitu:

(1) Susti, yaitu kawasan lahan yang diijinkan untuk diolah/digarap atau dijadikan kebun; (2) Nimahanti, yaitu kawasan ladang yang sedang ditinggalkan selama masa bera (masa istirahat lahan) selama lebih kurang 7 tahun (Gambar 1) yang dapat dikatakan sebagai kawasan lahan cadangan (reserved area). Pada kawasan ini boleh mengambil kulit kayu, rotan, akar pohon, daun, menanam pohon/tanaman kebun namun tidak boleh dijadikan tempat tinggal. Jika terpaksa, kawasan Nimahanti boleh dijadikan kebun; (3) Bahamti, adalah hutan yang tak boleh diganggu sehingga dapat disebut sebagai kawasan lahan konservasi, dan tidak boleh dijadikan ladang/kebun dan dijaga ketat oleh adat. Di hutan ini hanya boleh mengambil daun, kulit kayu dan rotan untuk membuat atap rumah; (4) Situmti, adalah bekas kebun ubi jalar (batatas), dekat dengan perkampungan atau tempat tinggal, termasuk pekarangan rumah, sebagai kawasan ladang menetap. Kawasan ini bercirikan sebagai lahan terbuka, rerumputan, kebun sayur, termasuk tempat menanam sayuran yang bisa dijual seperti daun bawang, wortel, kentang dan seledri.

Iskandar (1992) melaporkan zonasi dan tipologi lahan adat Suku Baduy, Banten Selatan sebagai berikut:

(1) Zona lembah pemukiman, setelah hutan dibuka, dan dijadikan perladangan atau kebun campuran, maka lahan dijadikan pemukiman secara berkelompok, dengan lahan pekarangan yang dikonservasi dan tidak boleh dibuka untuk ladang yang disebut sebagai hutan kampung (dukuh lembur). Lahan pemukiman ini biasanya datar dan dekat dengan sumber air atau sungai.

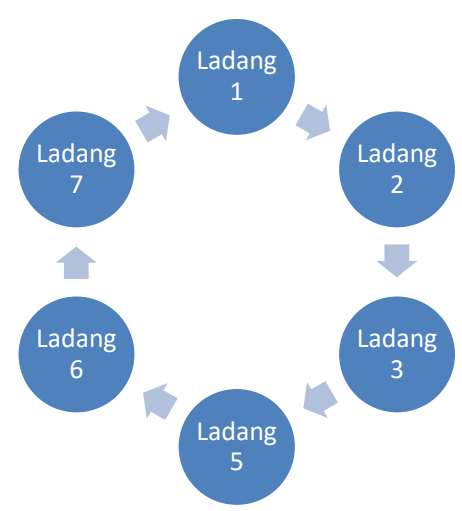

Gambar 1. Siklus ladang berpindah 7 tahun

(2) Zona perladangan dan kebun, berada di lereng dan lembah bukit digunakan sebagai ladang berpindah ladang menetap, dan kebun campuran. Pada zona ini terdapat lahan reuma atau lahan bero yang berupa semak belukar atau hutan sekunder hasil 
pemberoan pada sistem perladangan dimana setelah 3 tahun bero atau lebih dapat dibuka kembali sebagai ladang pangan atau kebun. Pada sebagian ladang, selalu ditanami ulang tanaman pangan dan sayur sehingga berupa ladang menetap. Pada sebagian lahan ladang disisipi berbagai tanaman menahun seperti pisang, dan di ladang Baduy luar dapat disisipi cengkeh, kopi, dadap, duku, manga dan lain-lain berubah menjadi kebun campuran.

\section{SAGU}

Budidaya sagu memperlihatkan perkembangan sistem pertanian tradisional. Sampai saat ini tradisi makanan pokok berupa sagu yang diperoleh dari hutan sagu masih umum ditemui di Maluku, Papua, dan Sulawesi terutama di wilayah pesisir. Makanan pokok dari sagu yang paling populer di Maluku dan Papua disebut papeda. Pangan utama ini dibuat dari aci sagu yang disuspensikan dalam air dingin kemudian disiram air mendidih sehingga mengental seperti lem. Di Sulawesi Tenggara makanan utama terbuat dari sagu disebut sinonggi yang cara membuatnya hampir sama dengan membuat papeda yaitu sagu disiram dengan air mendidih sehingga mengental matang. Sistem perolehan pangan dengan mengumpul hasil hutan, berburu, dan mencari ikan terus berlanjut dibarengi pula dengan mulai membudidayakan tanaman, ternak, dan ikan.

Untuk memperoleh sagu untuk makanan sehari-hari, orang Papua menempuh dua strategi ke dusun sagu, yaitu hutan sagu. Pertama, strategi jarak pendek yakni, pergi-pulang dari kampung ke dusun sagu karena jangkauannya dekat. Keluar pagi dan pulang sore hari dengan membawa hasil. Kedua, strategi jarak panjang yakni, pergi beberapa lama tinggal di dusun sagu, dengan membangun sebuah rumah untuk dihuni. Mereka hidup di hutan-hutan sagu dengan menetap di suatu tempat untuk beberapa waktu, lalu pindah mencari tempat baru adalah apabila makanan di tempat itu sudah mulai berkurang. Inilah yang menyebabkan mereka sering meninggalkan kampungnya. Anak-anak biasanya diikutsertakan dalam kegiatan pencarian makan ini (Apomfires, 2002).

Studi tentang etnobotani tanaman pangan tradisional Papua sudah cukup banyak. Kanro et al. (2003) melaporkan bahwa pengetahuan masyarakat Papua tentang budidaya sagu diperoleh secara turun temurun dan berkembang sebagai tradisi dan mitos. Tradisi bertanam sagu yaitu meliputi pemilihan jenis sagu berproduksi tinggi, pemilihan bibit, cara tanam, dan pemeliharaan tanaman menggunakan teknologi yang sederhana, mendasarkan pengalaman dan potensi sumberdaya yang ada sehingga dapat berbeda antara wilayah atau suku sebagai kearifan lokal. Banyaknya ragam spesies dan varietas pohon sagu menunjukkan bahwa sagu merupakan tumbuhan asli setempat dan sudah lama dimanfaatkan sebagai sumber bahan pangan dan dikembangkan untuk membuat beragam makanan lokal.

\section{UBI JALAR}

Sistem budidaya pertanian yang awal adalah berupa sistem perladangan berpindah dengan bahan tanam vegetatif seperti talas, pisang, singkong, gembili dan ubi jalar. Selain sagu, sampai saat ini ubi jalar merupakan makanan pokok di Papua New Guinea (Michael, 2020) dan sebagian wilayah di Propinsi Papua, baik di wilayah pesisir maupun di pegunungan. Ubi jalar mampu beradaptasi dan berproduksi dengan baik dengan teknologi sederhana pada ketinggian 1.650-2.700 m dpl., seperti di kawasan Lembah Baliem, Kabupaten Jayawijaya.

Indonesia merupakan salah satu pusat keanekaragaman genetik ubi jalar terbesar di Asia Pasifik. Schneider (1995) menyebutkan di dataran tinggi Papua mencatat terdapat 450 varietas dan di Lembah Baliem mencatat 200 varietas lokal ubi jalar. Setelah 
introduksi pada beberapa ratus tahun yang lalu, ubi jalar meluas dan dapat beradaptasi sampai dataran tinggi dan ditanam sebagai ladang berpindah sebagaimana tanaman ubiubian yang sebelumnya ada seperti talas dan gembili. Sistem ladang berpindah yang membiarkan lahan menjadi belukar atau hutan sekunder memungkinkan tanaman ubi jalar berbunga saling bersilang antar varietas yang ditanam, menghasilkan biji. Kemudian ladang dibuka kembali, dibabat dan dibakar yang memungkinkan kulitnya yang keras dari biji-biji ubi jalar terbakar sehingga mudah berkecambah. Sebagian ubi jalar voluntir ini akut tumbuh dan berumbi bersamaan dengan ubi jalar yang ditanam oleh petani sehingga muncul varietas baru secara alami.

Banyaknya jenis-jenis ubi jalar yang ditanam diakibatkan oleh sistem pertanian tradisional melalui pola perladangan berpindah. Kebun atau ladang yang usai diusahakan apabila sudah kurang produktif akan ditinggalkan pemiliknya dan dibiarkan dengan tujuan sebagai makanan ternak (babi). Proses ini menyebabkan tanaman ubi jalar tumbuh menjadi liar dan terjadi perkawinan silang diantara jenis-jenis ubi jalar yang ada pada lahan tersebut sehingga menyebabkan jenis-jenisnya semakin banyak. Sistem pertanian tradisonal ladang berpindah sangat mendukung perkembangan jenis-jenis ubi jalar baru di Papua karena kebun yang tidak produktif lagi dibiarkan begitu saja tumbuh liar sehingga terjadi perkawinan silang diantara jenis-jenis tersebut akan menghasilkan jenisjenis baru. Kedaan demikian berlangsung secara terus-menerus sehingga membuat daerah pedalaman Papua menjadi pusat umbi-umbian terbesar di Indonesia dengan jumlah jenis yang banyak (Segenil et al., 2017).

Kearifan lokal dalam budidaya ubi jalar di Jayawijaya berdasarkan tipe agroekosistem, yaitu wen hipere, yabu waganak, yabu enaifpipme, dan yabu lome. Wen hipere adalah sistem budidaya ubi jalar dengan cara membuat parit-parit permanen pada daerah yang berair. Yabua dalah sistem penanaman ubi jalar di lahan kering. Sistem yabu terbagi atas beberapa cara tanam, bergantung pada tingkat kemiringan lahan. Kedua sistem budidaya tersebut telah dipraktekkan masyarakat Jayawijaya secara turun-temurun (La Achmady dan Schneider, 1993).

Bagi petani Suku Arfak, cara melakukan pemanenan adalah memanen secara bertahap. Petani tidak memanen seluruh ubi jalar sekaligus karena ubi jalar yang sudah di panen tidak bisa disimpan dalam waktu lama tanpa diolah. Sementara pengetahuan petani Suku Arfak tentang pengolahan ubi jalar agar dapat digunakan dalam waktu yang lama sangat terbatas. Oleh karena itu, petani membiarkannya di kebun dan akan dipanen jika persediaan di rumah telah habis. Biasanya ubi jalar yang dibiarkan di kebun akan terus berproduksi selama kurang lebih 3 sampai 4 bulan dan produktivitasnya akan semakin menurun. Petani Suku Arfak harus membuka kebun baru ketika ubi jalar dimulai panen. Hal ini dimaksudkan supaya ketika ubi jalar yang ditanam di kebun sebelumnya habis dipanen, petani tetap memiliki kebun ubi jalar yang sudah siap dipanen sehingga mereka tidak akan kehabisan bahan pangan (Matualage, 2011

\section{UMBI UWI}

Salah satu kelompok tanaman pangan yang sangat tradisonal sejak zaman prasejarah adalah umbi dari uwi-uwian (Discorea spp). Tanaman uwi memiliki ragam morfologi yang cukup luas, terdiri dari atas Dioscorea bulbifera (huwi buah), Disocorea nummularia (huwi upas), Dioscorea pentaphylla (huwi sawut/fibrous yam), Dioscorea pentaphyla, Dioscorea alata, Dioscorea esculenta (gembili), Disoscorea hispida (gadung), dan beberapa subspesies lainnya. Secara umum, yang membedakan satu subspesies dengan subspesies lainnya adalah arah lilitan dan bentuk batang, ada tidaknya duri pada 
batang, bentuk dan jumlah helaian daun, ada tidaknya buah, bentuk umbi, jumlah dan ukuran umbi, serta warna umbi (Flach dan Rumawas 1996).

Uwi sebenarnya sudah sejak lama merupakan tanaman budidaya, tetapi masih sangat jarang ditanam secara monokultur. Biasanya orang mengusahakan hanya dalam jumlah yang terbatas sebagai tanaman campuran sebagai penghasilan tambahan dan cadangan pangan terutama pada masim kering atau musim paceklik dimana makanan pokok utama tidak tersedia.

Di antara tanaman uwi penting adalah Gembili (Discorea esculenta) juga merupakan makanan pokok yang dibudidayakan pada sistem perladangan dan kebun campuran. Tanaman gembili tersebar di beberapa wilayah Papua, terutama di Merauke. Suku Kanum di Merauke sebagai salah satu subsuku Marind yang mendiami Taman Nasional Wasur mengonsumsi gembili secara turun-temurun sebagai makanan pokok. Namun saat musim paceklik atau belum memasuki masa panen gembili, penduduk melakukan kegiatan berburu dan sebagai pangan alternatifnya adalah sagu dan pisang.

Sistem budidaya gembili sudah menyatu dengan kehidupan masyarakat suku Kanum karena mempunyai nilai budaya yang tinggi, yaitu sebagai mas kawin serta pelengkap pada upacara adat. Dengan demikian, budidaya gembili bagi suku Kanum merupakan suatu keharusan. Masyarakat suku Kanum membudidayakan berbagai kultivar gembili, menamakan kultivar gembili berdasarkan karakter morfologi umbi. Sistem budidaya bergantung pada jenis gembili yang ditanam.

Umumnya gembili dibudidayakan dengan menggunakan tajar dari bambu dengan tinggi 2,50-4 m. Untuk menjamin keberlanjutan konsumsi, gembili yang dipanen disimpan di suatu tempat dalam rumah kecil yang diberi nama keter meng. Rumah kecil tersebut terbuat dari bambu dan beratapkan kulit kayu bus (Melaleuca sp.) agar gembili terhindar dari sinar matahari langsung (Rauf dan Lestari, 2009).

Selain gembili, di Jawa banyak ditemukan uwi yang berumbi besar, tidak beracun, yang merupakan jenis Discorea alata (dikenal sebagai water yam, greater yam). Tanaman ini berumbi tunggal, ukuran, bentuk dan warna umbi beragam misalnya coklat, hitam, putih, krem dan ungu. Jenis ini dibedakan menjadi beberapa golongan (1) kultivar ungu kompak, tanaman mengandung antosianin terutama di tangkai daun, umbi, dan korteks, (2) kutivar ungu primitif, tanaman mengandung antosianin di daun, tangkai daun, umbi biasanya tidak bercabang, korteks umbi merah segar ungu, (3) kultivar hijau primitif, daun berwarna hijau cerah, tanpa antosianin, umbi panjang berwarna putih cerah, kualitas masakan jelek, (4) kultivar kompak, daun memiliki antosianin, umbi pendek, besar, cerah, sedikit pewarnaan di korteks, kualitas masak baik, dan (5) kultivar sedikit putih, umbi soliter (tunggal), korteks berwarna segar keputihan (Trustinah, 2013).

Keragaman uwi ditemukan di D.I. Yogyarakata terutama di Kabupaten Gunung Kidul antara lain uwi beras, uwi beras legi, uwi beras butun, uwi bangkulit, uwi ungu (senggani), uwi luyung putih, uwi luyung kuning, uwi luyung ungu, uwi ulo, uwi jingking, uwi banggai, uwi kuning, uwi jingga, uwi hitam. Ragam jenis dan varietas uwi ditanam petani di ladang dan pekarangan yang paling banyak adalah gembili (Discorea esculenta), diikuti uwi (Discorea alata) dan gadung (Discorea hispida), sedangkan gembolo (Discorea bulbifera), tomboreso (Discorea pentaphylla), dan jebubuk (Discorea numularia) belum dibudidayakan dan dipanen dari hutan (Purnomo et al., 2012).

\section{TALAS}

Talas bentul atau taro (Colocasia esculenta) diduga merupakan tumbuhan asli Indonesia dan India, sedangkan talas kimpul atau balitung atau litung (Xanthosoma 
sagittifolium) diduga berasal dari daratan Asia. Walaupun diperbanyak secara vegetatif, tanaman talas mempunyai keragaman klon yang tinggi yang ditunjukkan oleh clonal richness index yang tinggi (Chair et al., 2016) sebagai hasil mutasi maupun reproduksi ketika tanaman diberokan. Pada sistem pertanian tradisional sehingga ditemukan tanaman yang berasal dari biji dan petani kemudian memanfaatkan persilangan spontan tersebut (Vandenbroucke et al., 2016). Maxiselly dan Karuniawan (2011) melaporkan adanya keragaman yang tinggi pada aksesi kedua jenis talas tersebut dari Jawa Barat. Prana (2007) melaporkan dari 20 kultivar bentul yang diteliti dapat dibagi menjadi 3 kelompok besar, yaitu kelompok kultivar yang selama pengamatan tidak pernah berbunga, kelompok kultivar yang berbunga sedikit (menghasilkan 1-3 perbungaan per kelompok perbungaan/ individu tanaman), dan kelompok kultivar yang berbunga banyak.

Talas merupakan makanan pokok Papua New Guinea dan merupakan makanan pokok penting di daerah Papua seperti di Ayamaru dan Biak Barat. Dilaporkan sekitar $60 \%$ masyarakat Ayamaru mengonsumsi talas sebagai makanan pokok. Meskipun demikian masyarakat di daerah lain di Papua juga mengonsumsi talas sebagai pangan alternatif bersama sagu, ubi jalar, dan talas. Talas merupakan salah satu tanaman makanan pokok tradisional yang paling kuno yaitu sudah dimakan sejak zaman prasejarah.

Talas raksasa atau giant taro (Cyrtosperma chamissonis) adalah talas asli Indonesia, sejenis talas dengan ukuran tanaman yang sangat besar, berbeda dari ukuran talas pada umumnya. Habitat asli tanaman ini antara lain di Pulau Mapia, pulau terluar di utara kepala burung Papua, Samudera Pasifik. Talas ini dibawa dan dikembangkan oleh petani lokal di Pami, Manokwari. Struktur daun talas mapia menyerupai daun tanaman keladi, namun umbinya merupakan umbi talas. Tinggi tanaman mencapai 4 meter. Panjang daun 1,5 meter, lebar daun 1 meter. Tanaman ini memiliki jumlah anakan sangat banyak $(>10$ anakan). Setiap anakan menempel pada umbi induk. Bobot umbi mencapai 14 kilogram dengan panjang umbi 0,5 meter. Pada tanah yang subur, panjang umbi mencapai 1-2 meter dengan bobot mencapai 40-60 kilogram. Warna umbi talas mapia kuning muda dan semakin dekat pangkal pelepah semakin berwarna kuning tua.

\section{JEWAWUT}

Jewawut sudah sejak lama dibudidayakan secara tradisional bahkan sudah digambar pada relief Candi Borobudur dan saat ini masih ditanam dan dikonsumsi di beberapa daerah di Indonesia diantaranya di Sulawesi Barat (Polewali Mandar), Bengkulu, Sumba, Papua, Buru dan Jawa Tengah (Wonogiri). Beberapa nama daerah untuk jewawut, diantaranya juwawut (Jawa), jewawut, kunyit (Sunda, Jawa Barat), tarreang (Polewali Mandar, Sulawesi Barat), hotong (Buru, Maluku), pokem (Numfor, Papua), witi (Bima), ba'tang (Enrekang, Sulawesi Selatan), sekoi (Bengkulu) (Juhaeti et al., 2019).

Jewawut merupakan sejenis tanaman serealia yang banyak dijumpai di Biak Numfor, dengan nama lokal pokem atau gandum Papua. Tanaman ini meliputi lima genera, yaitu Panicum, Setaria, Echinochloa, Pennisetum, dan Paspalum, semuanya termasuk dalam famili Paniceae. Jenis jewawut yang ditemukan di Papua termasuk spesies Setaria italica (pokem ekor macan) dan Pennicetum glaucum (pokem ekor kucing). Dari spesies tersebut ditemukan berbagai warna. Menurut masyarakat Biak Numfor dalam Rumbrawer (2003), ada lima jenis jewawut yang dijumpai di Biak Numfor, yaitu pokem vesyek (jewawut cokelat), pokem verik (jewawut merah), pokem vepyoper (jewawut putih), pokem vepaisem (jewawut hitam), dan pokem venanyar (jewawut kuning). Bagi penduduk Biak Numfor, jewawut telah 
lama dimanfaatkan sebagai bahan makanan pokok dan komoditas adat. Diduga orang Numfor telah berabad-abad hidup dengan budidaya jewawut sebagai pangan pokok selain umbi-umbian dan kacang hijau (Rauf dan Lestari, 2009).

Sistem bercocok tanam masyarakat di Pulau Numfor adalah ladang berpindah. Jumlah penduduk lokal yang masih sedikit belum menjadi masalah bagi penggunaan lahan dalam membuat ladang (kebun) di masing-masing kampung. Setiap warga (keluarga) mempunyai hak yang sama untuk membuka ladang di hutan. Tanaman utama yang diusahakan oleh masyarakat setempat adalah pokem (S. italica) dan kacang hijau. Selain kedua tanaman tersebut, masih ada jenis tanaman lain seperti ubi kayu (Manihot utilissima), ubi jalar (Ipomoea batatas), jagung (Zea mays), pepaya (Carica papaya), keladi dan jenis lainnya. Petani membuka ladang baru yaitu mempersiapkan lahan untuk bertani sebelum musim panen ladang produktif tiba dengan cara penebasan semak, penebangan pohon, dan pembakaran.

Pada saat memasuki musim kemarau benih disebar; seminggu kemudian benih sudah tumbuh. Apabila gagal tumbuh maka dapat diulangi penebaran benih. Sejak dilakukan penebaran benih, tanaman dibiarkan dan tidak pernah dilakukan perawatan dalam hal pengaturan jarak maupun penjarangan tanaman. Dengan demikian sering ditemui tanaman hidup bergerombol dalam jumlah yang banyak di beberapa titik penebaran. Hal ini menimbulkan efek yang besar terhadap hasil produk buah dengan ukuran bulir yang lebih pendek dan kecil. Banyak petani juga tidak melakukan pembersihan terhadap tumbuhan pengganggu (gulma) di lahan tanaman pokem (Suharno et al., 2015).

Secara lebih intensif maka jewawut dapat ditanam pada lahan yang sudah diolah dan ditanam pada bedengan menggunakan bibit hasil penyemaian dengan jarak $30 \mathrm{~cm}$ dalam barisan dan $70 \mathrm{~cm}$ antar barisan. Jika menanam dalam bentuk benih maka ditabur dalam larikan atau ditabur dalam lubang tugal dengan jarak tanam tersebut Penanaman tanaman tumpangsari, penyiangan gulma, dan pemupukan akan meningkatkan produktivitas lahan (Tirajoh, 2015).

\section{HANJELI}

Hanjeli (Coix lacyma-jobi L.) merupakan sejenis tumbuhan biji-bijian tropis dari suku padi-padian atau Poaceae. Tanaman ini berasal dari Asia Timur dan Malaya, namun sekarang telah tersebar ke berbagai penjuru dunia. Beberapa varietas memiliki biji yang dapat dimakan dan dijadikan sumber karbohidrat dan juga obat. Hanjeli adalah nama popular di daerah Jawa Barat (Sunda), sedangkan nama popular Indonesia adalah Jali atau Jali-jali. Tanaman ini menyebar di berbagai ekosistem lahan pertanian yang beragam dari daerah iklim kering, basah, lahan kering maupun lahan basah di Sumatera, Sulawesi, Kalimantan, dan Jawa. Ada dua varietas yang ditanam orang, yaitu Coix lacryma-jobi var. lacrymajob yang memiliki cangkang keras berwarna putih, bentuk oval dan dipakai untuk manikmanik. Varietas yang lainnya adalah Coix lacryma-jobi var. Mayuen yang dimakan orang dan juga menjadi bagian dari tradisi pengobatan (Kurniawan, 2014).

Tanaman hanjeli menyebar di berbagai ekosistem lahan pertanian yang beragam di daerah iklim kering ataupun iklim basah, lahan kering dan lahan basah seperti ditemukan di Sumatra, Sulawesi, Kalimantan. Di Jawa Barat, tanaman tersebut diusahakan oleh petani masih secara konvensional sebagai tanaman langka, secara sporadis ditemukan di Kabupaten Bandung di Punclut, Cipongkor, Gunung Halu, Kiarapayung, Tanjungsari Kabupaten Sumedang, Sukabumi, Garut, Ciamis dan Indramayu. Di Jawa Barat, tanaman ini banyak dibudidayakan oleh masyarakat sebagai tanaman selingan yaitu ditanam di ladang dan pekarangan secara tumpangsari. Secara monokultur, hanjeli secara tradisional ditanam di lahan marginal tanpa 
teknik budidaya yang intensif, tanpa pupuk dan pemeliharaan lainnya.

Sebagaimana berladang padi gogo dan jagung, hanjeli ditanam dengan cara ditugal pada jarak tanam umumnya $100 \times 50 \mathrm{~cm}$, dengan 2-3 biji per lubang. Potensi hasil berkisar antara 4-6 ton/ha biji berkulit atau 3-4 ton/ha beras hanjeli, serta bisa dipanen beberapa kali setelah dipangkas atau diratoon (Nurmala, 2010). Ketika dipanen, batang ditebas, biji dirontokkan, dijemur, ditumbuk menjadi beras hanjeli, dan ditumbuk lagi sehingga diperoleh tepung hanjeli. Tepung hanjeli dapat diolah menjadi berbagai makanan berbasis tepung seperi kue, brownies, bubur, tape, dodol, cendol, dan keripik.

\section{KESIMPULAN}

Sistem perladangan berperan penting dalam produksi dan ketahanan pangan petani. Sistem perladangan menetap dan perkebunan bertransformasi dari sistem pengumpulan hasil hutan dan sistem perladangan berpindah. Etnoagronomi perladangan pangan yang dilakukan secara tradisional seperti bertanam sagu dan ubi jalar di Papua, bertanam umbi uwi di Papua dan Daerah Istimewa Yogyakarta, bertanam talas di Jawa Barat dan Papua, bertanam jawawut di Jawa dan Biak Numfor, dan bertanam hanjeli di Jawa Barat merupakan kearifan lokal yang penting dalam pengembangan produksi dan industri pangan nonberas.

\section{DAFTAR PUSTAKA}

Apomfires, F. 2002. Makanan pada komuniti adat Kae: Catata sepintas dalam penelitian gizi. Antropilogi Papua, 1(2): 1-6.

Assa, V.R.,M. Mandoowen, A. Rumiak. 2013. Tanaman Pokem dalam tradisi lokal etnis biak di pulau Numfor kabupaten Biak Numfor. BPNB Jayapura

Barlow, C. and S.K. Jayasurija. 1986. Stages of development of smallholder tree crops agriculture. Development and Change, 17:635-658.

Chaïr H., R.R. Traore, M.F. Duval, R. Rivallan, A. Mukherjee, L.M. Aboagye, W.J. Van Rensburg, V. Andrianavalona, M.A.A.P. de Carvalho, F. Saborio, M.S. Prana, B. Komolong, F. Cramb, R.A. 2009. Agrarian transition in Serawak: Intensification and expansion reconsidered. ChATSEA Working Paper No 6. The Canada Research Chair in Asean Studies. 36 p.

Dove, M. 1994. Transition from native forest rubbers to hevea brasillensis (Euphorbiaceae) among tribal smallholders in Borneo. Economic Botany, 48(4): 382396.

Evizal, R. 2008. Intensitas lahan dan formasi agroforestry karet di Jambi: Dari ladang kembali ke hutan. Visi Jurnal Irigasi, Sumberdaya Air, Lahan dan Pembangunan, 27(1): 36-45.

Evizal, R. 2013. Etno-agronomi Pengelolaan Perkebunan Kopi di Sumberjaya Kabupaten Lampung Barat. Jurnal Agrotrop, 3(2): 1-12.

Hujairin, M., A. Ismadi dan T. Kustana. 2017. Revitalisasi kearifan lokal Suku Arfak di Papua Barat dalam rangka mendukung ketahanan pangan wilayah. Jurnal Prodi Manajemen Pertahanan, 3(1): 53-77.

Iskandar, J. 1992. Ekologi Perladangan Di Indonesia Studi Kasus dari Daerah Baduy Banten Selatan Jawa Barat. Djambatan. Jakarta. 145 p.

Juhaeti, T., W. Widiyono, N. Setyowati, P. Lestari, F. Syarif, Saefudin, I. Gunawan, Budiarjo, R.H. Agung. 2019. Serealia lokal jewawut (Setaria italica (L.) P. Beauv): Gizi, budidaya dan kuliner. Prosiding Seminar Nasional Biologi, Saintek dan Pembelajarannya Tahun 2019. Pp. 9-17.

Kanro, M.Z., A. Rouw, A. Widjono, Syamsuddin, Amisnaipa, dan Atekan. 2003. Tanaman sagu dan pemanfaatannya di Propinsi Papua. Jurnal Litbang Pertanian, 22(3): 116-124.

Kurniawan, H. 2014. Hanjeli dan potensinya sebagai bahan pangan. BB Biogen. http://biogen.litbang.pertanian.go.id/2014/ 
10/hanjeli-dan-potensinya-sebagai-bahanpangan.

La Achmady and J. Schneider. 1993. Sweet potato germplasm in Jayawijaya division of Irian Jaya diversity, problems, and pathways for conservation. Workshop on Farm Conservation, 6-8 December, International Potato Center-ESEAPCentral Research Institute for Food Crops, Bogor-Indonesia.

Lawac, V.L. 2016. Genetic Diversification and Dispersal of Taro (Colocasia esculenta (L.) Schott). PLOS ONE, 11(6): e0157712. doi:10.1371/journal.pone.0157712.

Manshur, F. 2019. Budidaya Hanjeli, Sebuah Strategi Kebudayaan. Odesa Indonesia. https://odesa.id/2019/03/budidaya-hanjelisebuah-strategi-kebudayaan.

Matualage, A. 2011. Keefektifan pembelajaran social kearufan lokal budidaya ubi jalar di kalangan Suku Arfak Kabupaten Manokwari. Kawistara, 1(1): 68-78.

Maxiselly, Y. dan A. Karuniawan. 2011. Keragaman talas spesies Colocasia esculenta (L.) Schott dan Xanthosoma sagittifolium (L.) Schott di Jawa Barat. Prosiding Seminar Hasil Penelitian Tanaman Aneka Kacang dan Umbi. Pp. 795-802.

Michael, P.S. 2020. Agriculture versus climate change - A narrow staple-based rural livelihood of Papua New Guinea is a threat to survival under climate change. Sains Tanah - Journal of Soil Science and Agroclimatology, 17(1): 78-93.

Nurmala, T. 2010. Potensi dan Prospek Pengembangan Hanjeli (Coix lacryma jobi L ) sebagai Pangan Bergizi Kaya Lemak untuk Mendukung Diversifikasi Pangan Menuju Ketahanan Pangan Mandiri. Pangan, 20(1): 41-48.

Prana, M.S. 2007. Studi Biologi Pembungaan pada Talas (Colocasia esculenta (L.) Schott.). Biodiversitas, 8(1): 63-66.

Purnomo, B.S. Daryono, Rugayah, I. Sumardi. 2012. Studi etnobotani Discorea spp. (Discoreacceae) dan kearifan budidaya lokal masyarakat di sekitar hutan Wonosari
Gunung Kidul Yogyakarta. Jurnal Natur Indonesia, 14(3): 191-198.

Raharjo, B., T. Arief, R.U. Somantri dan Wiratno. 2015. Eksplorasi dan Karakterisasi Sumber Daya Genetik Lokal Tanaman Pangan dan Hortikultura Spesifik Lokasi Sumatera Selatan. Prosiding seminar nasional sumber daya genetik pertanian. Pp. 21-31.

Rauf, A.W. dan M.S. Lestari. 2009. Pemanfaatan komoditas pangan lokal sebagai sumber pangan alternatif di Papua. Jurnal Litbang Pertanian, 28(2): 54-62.

Schneider, J. 1995. Farmer practices and sweet potato diversity in highland New Guinea. In Schneider, J. (Ed). Indigenous Knowledge in Conservation of Crop Genetic Resources: Proceedings of an International Workshop. Pp. 63-70.

Segenil, K., L.Y. Chrystomo, dan M. Warpur. 2017. Pengetahuan Tradisional Masyarakat Suku Nyalik tentang Ubi Jalar [Ipomoea batatas (L.) Lam.] di Distrik Silimo, Kabupaten Yahukimo Papua. Jurnal Biologi Papua, 9(1): 8-13.

Suharno, S. Sufaati, V. Agustini dan R.H.R. Tanjung. 2015. Usaha domestikasi tumbuhan pokem (Setaria italic (L) Beauv) masyarakat lokal Pulau Numfor Kabupaten Biak Numfor sebagai upaya menunjang ketahanan pangan nasional. Jurnal Manusia dan Lingkungan, 22(1): 73-83.

Tirajoh, S. 2015. Pemanfaatan Jawawut (Setaria italica) Asal Papua sebagai Bahan Pakan Pengganti Jagung. Wartazoa, 25(3): 117124.

Trustinah. 2013. Karakteristik dan keragaman morfologi uwi-uwian (discorea sp). Prosiding Seminar Hasil Penelitian Tanaman Aneka Kacang dan Umbi 2013. Pp. 717-726.

Vandenbroucke, H., P. Mournet, H. Vignes, H. Chair, R. Malapa, M.F. Duval, V. Lebot. 2016. Somaclonal variants of taro (Colocasia esculenta Schott) and yam (Dioscorea alata L.) are incorporated into farmers' varietal portfolios in Vanuatu. Genet Resour Crop Evol, 63:495-511. 